\title{
UITDAGING VIR VOLWASSENE DIDAKTIEK: BEGELEIDE SELFSTUDIE DIE OPLOSSING?
}

\section{H Klopper}

This is a paper which was delivered by Hester Klopper at the Nursing Education Association National Congress held on 26-28 August 1993 at the University of Cape Town. Dr Klopper was awarded the HAUM medal and prize for this paper, judged the best delivered at the conference.

Referaat gelewer by Nasionale Kongres van die Verpleegonderwys Vereniging, 26-28 Augustus 1993, by die Universiteit van Kaapstad. Hierdie referaat verower die HAUM kontantprys en -medalje as eerste prys vir die beste referaat gelewer tydens die kongres.

\section{SAMEVATTING}

Die huidige onderrigbenadering in Verpleegkunde is meestal dosentgesentreerd: gedurende ' $n$ formele lesing voorsien die dosent al die feite, terwyl die student ' $n$ passiewe luisteraar is wat die feite moet memoriseer en tydens evaluering net so weergee. In hierdie referaat ward 'n betoog gevoer vir 'n studentgesentreerde onderrigbenadering wat onafhanklike selfstudie impliseer met begeleiding van die leerbegeleier waar nodig. Die rasionaal wir hierdie denkwyse is dat die student aangespoor moet word tot kwalitariewe akademies-wetenskaplike vorming, aangesien dit in die huidige tydvak dit onmoontlik is om die student van alle inligting te voorsien. Van die student word vereis om lewenslank' n leerder te bly... "A student cannot claim to have been educated successfully at university or college unless he has learned to study independantly".

\section{SUMMARY}

The current teaching approach in nursing is mainly tutor-centred: during a formal lecture the tutor provides the facts, the student stays a passive listener and has to memorize facts for reproduction during evaluation. In this paper the argument is focused on a student-centred approach that implies selfstudy with accompaniment when needed. The rationale for this approach is to develop a academic-scientific student, as it is impossible to provide all the information to learners in this technological despensation. The student is expected to remain a lifelong tearner ..."A student cannot claim to have been educated successfully at university or college unless he has learned to study independantly".

\begin{abstract}
"Although adults may or may not differ from preadults in respect to the basic cognitive processes of learning, the context of adult education differs sub stantially from the context of pre-adulthood. Hence they should be educaled differenily from preadults" (Beder.1989:48).
\end{abstract}

\section{INLEIDING}

Die doel van hierdie referaat is om te besin oor die funksionaliteit naliteit van begeleide selfstudie in Verpleegkunde. Wanneer literatuur oor volwassenconderwys in

\subsection{Leervermoë}

Volgens Cross (1981:163) en Wlodkowski (1986:10) dui die volwassene se uithouvermoë min agteruitgang soos die volwassene ouer word, mits leerinhoud aanvanklik effektief geleer is. Leerinhoud wat as sinvol en betekenisvol ervaar is, word op ' $n$ dieper vlak gekodeer en kan maklik herroep word (De Wet, Monteith \& Van Der Westhuizen, 1981:280).

\subsection{Selfkonsep}

Volgens Knowles (1980:44) ondergaan 'n persoon se persepsie van homself ' $n$ verandering tydens die volwasse wordingsproses vanaf ' $n$ afhanklike persoon na 'n selfrigtinggewende en selfregulerende persoon. Verantwoordelikheid en selfbepaling is wesenlike eienskappe van volwassenheid.

\subsection{Ervaring}

Knowles (1980:78), Jarvis (1983:83) en Rogers (1986:28) wys daarop dat die volwassene se ervaring 'n ryk hulpbron vir leer is. Die volwassene beskik oor 'n wye ervaringsveld, daarom kan nuwe leerstof makliker deur die volwassene-leerder met sy bestaande kennisstrukture geintegreer word en kan leer vergemaklik word.

\subsection{Leergereedheid}

Die volwassene openbaar leergereedheid na aanleiding van probleme of uitdagings uit sy lewenswerklikheid waarmee hy gekonfronteer word (Darkenwald \& Merriam, 1982:86-87). Die volwassene se leergereedheidmoment mag intree wanneer hy die bereiking van 'n spesifieke doel voor oè het, of wanneer hy ervaar dat hy ontoereikend toegerus is om aan die eise van sy beroep te voldoen (Gravett, 1991:40).

\subsection{Leeroriëntasie en tydsperspektief}

Die volwassene openbaar behoefte aan onmiddellike toepassing en hou verband met die volwassene se ervaring van tyd. Die volwassene ervaar tyd korter en toon daarom die behoefte om op probleme van onmiddellike belang te fokus (Brundage \& Mackaracher 1980:35-36).

Vervolgens word kortliks gefokus op die eienskappe van die volwassene-leerder. 
verpleegstudent (leerder) waarskynlik aan die kenmerke van die volwassene-leerder, weens die eise ten opsigte van die verantwoordelikheid vir pasiëntsorg.

\section{KONSTRUKTIVISTIESE PERSPEKTIEF OP LEER}

Die hedendaagse konstruktivistiese perspektief op leer is beïnvloed deur die belangrike sieninge van Piaget se siening van die kind se ontwikkeling as 'n konstrueringsproses, Ausubel se konsep van betekenisvolle leer, Vygotsky se sosiale konstruktivisme, die kognitiewe psigologie en die kognitiewe wetenskap.

\subsection{Leer as konstruering van kennis}

Binne die konstruktivistiese raamwerk word leer as 'n aktiewe konstrueringsproses beskou. Die leerder is 'n aktiewe konstru- eerder van sy eie begrip en kennis......"To learn about something, to come to understand it, is in current cognitive science parlance, to construct a mental model" (Resnick, 1989:4). Vanuit hierdie stelling word bevestig dat die leerder nie 'n passiewe ontvanger van kennis is nie, maar ' $n$ aktiewe konstrueerder vant sy eie kennis, deurdat hy die nuwe inligting wat hy ontvang, verwerk in die lig van en aan die hand van sy bestaande konsepsies (Shephard, 1991:8; Resnick, 1989:1). Die leerder se bestaande konseptuele konteks of denkvoorstellings (kennis) speel 'n onlosmaaklike rol, omdat dit as interpratiewe raamwerk dien vir kenniskonstruering. Begrip van nuwe inligting word gelei en bepaal deur die bestaande konsepsies van die leerder.

Strike en Posner (1985:219) omskryf begrip as "....entails finding a niche within a conceptual ecology". 'n Konseptuele ekologie dui op hoe konsepte met mekaar verband hou en van mekaar afhanklik is. Resnick (1989:3) toon aan dat kennis slegs behou word wanneer dit ingebed is ' $n$ organiserende struktuur. Inligting wat slegs gememoriseer word sonder dat daar aktiewe verbandlegging plaasvind, tussen nuwe inligting en bestaande kennis en tussen nuwe inligting onderling, en sonder begrip vir die voorwaardelike gebruik van die kennis, kan gevolglik nie as kennisbasis dien vir probleemoplossing nie. Van belang is die herkenning dat daar in die proses van die konstruering van nuwe kennis terselfdertyd 'n herkonstruering van bestaande konsepsies plaasvind. Smith (1991:49) stel dit "...for while understanding requires relating new information to prior knowledge, the prior knowledge - part of the sense-making apparatus itself - must change". Gevolglik kan geredeneer word dat indien die student die nuwe inligting wel met 'n bestaande konseptuele raamwerk in verband kan bring en nuwe sinvolle verbande kan konstrueer, daar sprake is van konseptuele verandering wat plaasvind.

\subsection{Leer as konseptuele verandering}

Konseptuele verandering behels 'n kwalitatiewe verandering in die wyse waarop ' $n$ persoon ' $n$ fenomeen of aspek van die werklikheid ervaar, verstaan en konseptualiseer (Ramsden, 1992:4; Biggs, 1989: 10; Hounsell, 1984:192). Die fenomeen of aspek van die werklikheid wat hier ter sprake is, sluit in die doel van leer vanuit hierdie perspektief, as die aankweek van 'n denkhouding en -ingesteldheid by die leerder tipies van 'n kundige op die betrokke gebied.

Vanuit die konstruktivistiese perspektief, behoort die bestudering van inligting in hoofsaak te fokus op begrip. Verwerwing van feitelikhede is wel belangrik, maar behoort egter nooit ' $n$ doel in sigself te wees nie, maar altyd ' $n$ middel tot die doel van konseptuele verandering. Pines en West (in West, 1986:61-62) meld dat daar drie vlakke van konseptuele verandering onderskei kan word, naamlik:

- konseptuele ontwikkeling: behels die saamtrek en in verband bring van verskillende individuele komponente van kennis. Persoonlike begrip kom tot stand deur die verbandlegging van verskillende dele met mekaar en die samevoeging in 'n georganiseerde geheel;

- konseptuele oplossing: die regstelling of aanpassing van ' $n$ bestaande konsepsie aan die hand van nuwe inligting (personal sense-making); en

- konseptuele omruiling: 'n proses wat vereis dat die leerder 'n diepgewortelde konsepsie van 'n saak omruil vir 'n ander konsepsie.

Dit is dus egter belangrik om te besef, dat die blote aanbied van korrekte inligting deur 'n dosent as geen waarborg dien dat konseptuele verandering by studente sal plaasvind nie. Konsep- tuele verandering vereis aktiewe kognitiewe meewerking van die student.

\section{RASIONAAL VIR 'N ALTERNATIEWE ONDERRIGSTRATEGIE IN VERPLEGING}

Volgens die uitgangspunt van Knowles se beskrywing van die eienskappe van volwassene-leerders, voldoen die verpleegleerder waarskynlik aan die kenmerke van die volwassene-leerder weens die eise en verantwoordelikheid van pasiëntsorg.

McDermott (1984:31) verwys daarna dat studente ten spyte van die verwerwing van omvangryke feitelikhede en die suksesvolle afleggings van eksamens, nie die belangrike konsepte en beginsels wat die verworwe feitelikhede ten grondslag lê, begryp nie. Dit impliseer dat studente slegs die denkvaardighede van memorisering en samestelling benut. Om as onafhanklike verpleegpraktisyn te funksioneer is dié twee genoemde denkvaardighede onvoldoende. Om die wetenskaplike metode van verpleging toe te pas, word die verdere krities belangrike denkvaardighede van toepassing, analise, sintese en evaluering, benodig. Wanneer hierdie denkvaardighede bemeester is kan die verpleegkundige as onafhanklike praktisyn funksioneer met kreatiewe toepassing van kennis. Sy is dan waarskynlik 'n krities analitiese denker.

Dit is duidelik dat daar gefokus moet word op 'n onderrigmetode wat gekenmerk word deur groter buigsaamheid om die onderrig en leer (konstruktivistiese perspektief) van die volwassene-leerder te akkommodeer en sodoende die verpleegkundige te begelei na selfstandigheid en effektiewe funksionering as onafhanklike verpleegpraktisyn. Klopper (1992:12) bespreek begeleide selfstudie as so 'n onderrigstrategie en sê voorts "...begeleide selfstudie is 'n doelbewuste, gerigte leiding en steungewing aan die leerder deur middel van interaksie tussen die leerbegeleier en leerder". Die interaksie word gekenmerk deur die leerbegeleier se intensionele skep van 'n konteks bevorderlik vir leer, met die erkenning aan die leerder se behoefte aan selfrigtinggewendheid.

$\mathrm{Na}$ aanleiding van die veranderende sosiale konteks is dit van belang om aandag te skenk aan die proses van bemagtiging ("empowerment"). Die agtergelatenes het behoeftes aan die benutting van hulpbronne om hul eie probleme op te los. Bemagtiging spreek twee kritieke aspekte aan.

Eerstens, die spesiale verhouding tussen die professie en die samelewing en tweedens die verband tussen standaarde van die praktyk en standaarde van onderrig. Bemagtiging word deur Gibson (1991:354) gedefinieer as "....a social process of recognizing, promoting and enhancing people's abilities to meet their own needs, solve their own problems and mobilize the necessary resources in order to feel in control of their own lives". Begeleide selfstudie as onderrigstrategie mak voorsiening vir die leerder om teen 'n eie tempo te leer, met die beskikbaarheid van 'n leerbegeleier. Deur die benutting van begeleide selfstudie word die geleentheid geskep vir die agtergelatenes om vaardighede en kennis te verbeter, volgens geïdentifiseerde behoeftes, en neem die individu weer beheer van sy eie lewe.

Crouse (1988:1) stel dit onomwonde dat weens die snelle pas van verandering, wat ons tydsgewrig kenmerk, kan die leerbegeleier nie meer alleen die leerder voldoende toerus vir die eise wat aan hom gestel word nie. Lewenslange leer is ' $n$ noodsaaklikheid vir enige individu wat wil tred hou met die snelle pas van verandering. Crouse (1988:1) verwoord die gedagte as volg: "die stelsel-matige ontwikkeling van vermoëns, wat eventueel toerusting bied vir lewenslange selfstudie en verbeeldingryke toepassing van kennis op 'n hoë intellektuele en wetenskaplike vlak." Wlodkowski (1986:9203) steun hierdie stelling as volg: "When adults see themselves as the locus of 
causality for their learning, they are much more likely to be intrinsically positive motivated".

Crouse (1988:2) beklemtoon dat in die lig van finansiële besnociing van tersiêre onderrig is die implikasie dat daar op alle vlakke gerasionaliseer moet word sonder om doeltreffendheid in te boet. Groter doeltreffendheid sal moet bewerkstellig word in terme $v$ an beter tydsbenutting $v$ an leerbegeleiers, en daarmee saam beter akademiese prestasies van leerders (Smith, 1988:1). Die betoog is vir 'n meer doelgerigte en effektiewe onderrigstrategie en filosofie. Crouse (1988:2) bepleit die effektiwiteit deur die veronderstelling dat begeleide selfstudie' $n$ essensiële klemverskuiwing teweegbring vanaf onderrig na leer, of te wel, vanaf doseer na bestuur van leer. Die leerbegeleier skep op ' $n$ intensionele wyse 'n konteks wat bevorderlik is vir leer binne die verskynsel begeleide selfstudie. Daar is dus 'n oorgang van onderriggewer na leerbegeleier. Deur die bestuur van begeleide selfstudie sal van elke leerbegeleier verwag word om noukeurig te beplan, goed te organiseer, sterk begeleiding te gee en effektief, maar buigsaam te beheer (Crouse, 1988:3). Die leerkonteks word dan by uitstek dialogies - koöperatief ('n mutualistiese verhouding) en het die leerbegeleier dan die geleentheid om daadwerklik probleemgevalle te identifiseer onder leerders met die oog op vroegtydige remediëring.

Begeleide selfstudie impliseer nie dat die leerder volkome selfstandig en onafhanklik studeer nie. Die leerbegeleier tree op as beplanner, organiseerder, leier, bestuurder en motiveerder (Du Plessis, 1986:3). Die voordele van die begeleidingsrol van die leerbegeleier wat begeleide selfstudie as onderrigmetode gebruik is dat die onderrigbeginsel van individualisering meer tot sy reg kom. Alle leerders leer nie teen dieselfde tempo nic, maar met begeleide selfstudie vorder die leerder teen die tempo wat vir hom geskik is en kry hy die nodige begeleiding van die leerbegeleier om inhoude self te bemeester. Empiriese studies toon aan dat sodra die leerder self aktief raak, neem die leertempo toe en word retensie bevorder. Die geleentheid is dan daar dat die leerbegeleier tydens kontak met die leerders aandag gee aan beginsels, verbande en begrippe en nie die gee van inligting nie (Du Plessis, 1986:4).

$\mathrm{Na}$ die besinning van verskeie perspektiewe dat begeleide selfstudie moontlik die oplossing bied vir die andragogies-didaktiese situasie, word die waarde van begeleide selfstudie beskryf.

Die waarde van begeleide selfstudie as didaktiese middel word gevind in die didaktiese wesenskenmerke wat die onderrigstrategie funksionaliseer. Smith (1988:3-4) verken die vyf didaktiese wesenskenmerke in besonderhede. Eerstens, indien die leerder die geleentheid kry om nie net met feitekennis te doen te kry nie, maar 'n insig verkry in hoe by die feite uitgekom word, hoe eerder kan die leerder met ' $n$ korpus van samehangende inhoude oor die weg kom. Bereik die leerder nooit dié stand, bly die leerder afhanklik van die leerbegeleier vir rigtingaanwysing (vergelyk ook Kruger, 1979:37). 'n Tweede didaktiese wesenskenmerk is dat konstruktivistiese leer, eerder as behaviouristiese leer bevorder word. Konstruktivistiese denke word bevorder deur die kurrikulum en leerinhoude so an te bied dat die leerder gestimuleer word om reflektief te dink en effektiewe oplossingsmetodes te probeer aanwend. Die werkswyse lei die leerder tot die vroeë bemeestering van metodes vir probleembenadering en probleemoplossing. Hier- teenoor staan behaviouristiese leer waar die leerbegeleier die leerder voorsien van klaar antwoorde en oplossings in plaas van die konfrontasie met probleemvrae.

Die derde didaktiese wesenskenmerk is die wisseling van ostensiewe leer teenoor heuristiese leer. Met ostensiewe (aantonende) leer word leerinhoude in 'n finale vorm voorgehou, wat daartoe aanleiding gee dat die leerder die inhoude moet memoriseer, sonder om rekenskap te gee waaroor die inhoud handel. Heuristiese (ontdekkende) leer daarenteen, vereis dat die leerder insig toon in die onderliggende konsepte. Die leerinhoud word dan as betekenisvol ervaar, omdat die leerder die inhoud sowel as die waarde daarvan vir homself ontdek het. Insigleer en blywende leer vind dus plaas (vergelyk ook Kruger, 1979:37). Die vierde didaktiese wesenskenmerk is dat die leerder a angemoedig word om fenomene in vakverband krities te beskou en 'n kritiese ingesteldheid ontwikkel. Die leerder kan in die samehangende leer-inhoude delf en leer hy deur 'n kritiese ingesteldheid om tot in die nukleus van 'n saak in te dring. Vakinhoude is dan nie meer vir die leerder los analitiese inhoude nie.

Die vyfde didaktiese wesenskenmerk wat Smith (1988b:4) na verwys is dat 'n selfstudie gerigte model gekenmerk word deur 'n geleidelike oorgang van leiding gee na begeleiding. Die leerbegeleier begelei die leerder om self die leerstof te ontsluit, dit te verantwoord en aan kritiek van mede-leerders onderwerp. Deur die verkenning van die vyf didaktiese wesenskenmerke van begeleide selfstudie is dit duidelik dat selfstandige denke, insig, kritiese ingesteldheid, ' $n$ navorsingsingesteldheid en die vermoë om verworwe kennis toe te pas, nagestreef word.

Die afleiding is dus dat begeleide selfstudie op sterk didaktiese pilare rus met groot en kreatiewe moontlikhede vir toepassing in Verpleegkunde.

\section{SAMEVATTING}

Leerderkarakteristieke van die volwassene-leerder dien as aannames vir die wyse waarop die andragogies-didaktiese situasie (leerkonteks) geskep moet word.
Vanuit dié standpunt en die konstruktivistiese leer perspektief sal die konteks wat bevorderlik is vir leer as volg uitsien: - 'n dialogies-koöperatiewe karakter
vertoon;

- die benutting van begeleide selfstudie as onderrigstrategie sal gerig wees op die benutting van die volwassene se ervaring:

- selfrigtinggewendheid bevorder;

- die leerkonteks gekenmerk word deur gekontroleerde informaliteit, onderlinge respek, ondersteuning en vryheid van standpunt;

- die evalueringstegnicke wat geümplementeer word, die volwassene se perspektief, insig, integrasievermoë, ervaring en interpretaisevermoë benut; en

- die leerbegeleier vakdeskundig wees, 'n vaardige leerfasiliteerder wees en empaties optree.

\section{VERWYSINGS}

BEDER, H (1989): Purposes and philosophies of adult education. (In: Merriam, SB \& Cunningham, PM eds 1989 : Handbook of adult and continuing education. San Francisco : Jossey-Bass).

BIGGS,JB (1988): The role of metacognition in learning. Australia Joumal of Education. 32(2), 1988:127-138.

BRUNDAGE, DH \& MACKARACHER, D (1980): Adult learning principles and their application to program planning. Toronto : Ontario Institute of Studies in Education.

CROSS, KP, (1981): Adults as learners. Increasing participation and facilitating learning; second edition. San Francisco : Jossey-Bass.

CROUSE, CF (1988): Onderrigstrategie: Is ons nog op die spoor? Johannesburg: RAU (Ongepubliseerd)

DARKENWALD, GG \& MERRIAM, SB (1982): Adult Education: Foundations of practice. New York : Harper \& Row.

DE WET, JJ; MONTEITH, JL de K \& VAN DER WESTHUIZEN, GJ (1981): Opvoedende leer; derde druk. Durban: Butterworths.

DU PLESSIS, SJP (1986): Begeleide selfstandige studie. Didaktikom. 7(2), September, 1986:3-7.

GIBSON, CH (1991): A concept analysis of empowerment. Journal of Advanced Nursing 16, 1991:354-361. 
GRA VET T, SJ (1991): 'n Leerdergesentreerde benadering tot die formele andragogies-didaktiese situasie. Johannesburg : RAU (M.Ed. Verhandeling).

HOUNSELL, D (1984): Understanding teaching and teaching for understanding (In: Marton, F; Hounsell, D \& Entwistle, N eds 1984. The experience of learning. Edinburgh: Scottish Academic Press: 189-210).

JARVIS, P (1983): Adult and continuing education. Theory and practice. New York: Nichols Publishing Company.

KLOPPER, HC (1992): 'n Oriënteringsprogram vir verpleegkundiges in 'n privaathospitaal. Johannesburg: RAU (M. Cur.-verhandeling).

KNOWLES, MS (1980): The modern practice of adult education, from pedagogy to andragogy. New York: The Adult Education Company.

KRUGER, RA (1979): Studentedeelname in 'n didaktiese opset met minder kontakperiodes. Bulletin vir Dosente. RAU. 12(2), Oktober 1979.

McDERMOTT, LC (1984): Research on conceptual understanding in mechanics. Physics today, 37, 1984:24-32.
PINES, LA \& WEST, LHT (1986): Conceptual understanding and science learning : An interpretation of research within a source-of-knowledge framework. Science Education. 70(5), 1988:583-590.

RAMSDEN, P (1992): Learning to teach in higher education. London: Routledge.

RESNICK, LB (1989): Knowing, learning and instruction. Essays in honour of Robert Glazer. Hillsdale : Lawrence Erlbaum.

ROGERS, A (1986): Teaching Adults. Milton Keynes : Open University Press.

SHEPHARD, LA (1991): Psychometricians beliefs about learning. Education Researcher, (20)6, 1991:2-16.

SMITH, DPJ (1988): Implikasies van begeleide selfstudie. Johannesburg: RAU (Ongepubliseerd).

SMITH, DPJ (1988b): Begeleide selfstudie as onderrigmodel : Gevallestudie in die Opvoedkunde. Johannesburg: RAU (Ongepubliseerd).

SMITH, EL (1991): A conceptual change model of learning science. (In: Glynn, SM; Yeany, RH \& Britton, BK eds. 1991: The psychology of learning science. Hillsdale : New Jersey: 43-64).
STRIKE, KA \& POSNER, GJ (1985): A conceptual change view of learning and understanding ( $\mathrm{ln}$ : West, HT \& Pines. AL eds. 1985: Cognitive structures and conceptual change. Florida : Academic Press: 211-231).

WLODKOWSKI, $\mathbf{R}$ 1986: Enhancing adult motivation to learning. A guide to improving instruction and increasing learner achievement. London: Jossey-Bass.

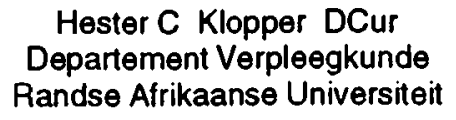

